These are medical assistants who spend 3 years studying medicine before graduating to work in general medicine. After about a year, some of the clinical officers return to Chainama College for an extra year, to become psychiatry clinical officers.

\section{Challenges and way forward}

\section{Government policy and legislation}

While some progress has been made in putting forward the mental health agenda for government policy, much remains to be done to convince not only government but also parliament of the importance of a robust mental health policy and infrastructure. Successful lobbying cannot be achieved by locals alone but requires the help of international partners such as the World Health Organization and the World Psychiatric Association.

\section{Human resources}

There is a serious deficit of trained personnel in the medical field. This is even more pronounced in mental health. Zambia needs more psychiatrists just to help build capacity in the mental health services, let alone to run such services. There is also a need for other mental health professionals, including psychologists and occupational therapists. To address this deficit, local training must be developed. Training people overseas, as has been proved over the years, is not a viable option. The establishment of training facilities will be expensive, nonetheless.

\section{Infrastructure}

There is a need to have mental health beds in every district. Every district has a general hospital and, to keep costs down, some of these could be allocated to psychiatry.

\section{Stigma}

High levels of stigma exist not only against those who are mentally ill but also against their families and those working in the mental health services. Many patients are disowned by their families. Most long-stay patients in Chainama Hospital have no contact with their family members. The 'out of sight out of mind' mentality is prevalent.

Public awareness campaigns are needed. These could be targeted at schools, colleges, workplaces and other public areas. One or two charities are trying but, with limited capacity, little is being achieved. The government may decide to make this one of the priorities for mental health. It is certainly an achievable goal which, unlike the above, does not require massive funding.

\section{Sources}

Haworth, A. (1988) Psychiatry in Zambia. Bulletin of the Royal College of Psychiatrists, 12, 127-129.

Mayeya, J., Chazulwa, R., Mayeya, P. N., et al (2004) Zambia mental health country profile. International Review of Psychiatry, 16, 63-72.

Mwanza, J., Sikwese, A., Banda, M., et al (2008) Phase 1 Country Report. Mental Health Policy Development and Implementation in Zambia: A Situation Analysis. WHO. Available at http://www.who. int/mental health/policy/development/Zambia\%20Country\%20report. pdf (last accessed January 2009).

\title{
Correlates of lifetime alcohol abuse and dependence among older community residents in Brazil
}

\author{
Gerda G. Fillenbaum, ${ }^{1}$ Sergio Luís Blay, ${ }^{2}$ Sergio Baxter Andreoli ${ }^{2}$ and \\ Fabio Leite Gastal ${ }^{3}$
}

${ }^{1}$ Center for the Study of Aging and Human Development, Duke University Medical Center, and Geriatric Research, Education and Clinical Center, Veterans Administration Medical Center, Durham, NC, USA, email ggf@geri.duke.edu ${ }^{2}$ Department of Psychiatry, Federal University of São Paulo, Brazil (Escola Paulista de Medicina - UNIFESP) ${ }^{3}$ Invited Professor, Medical University of Minas Gerais/UFMG, Brazil

$\mathrm{M}$ isinterpretation in major surveys of alcohol use disorder as described by DSM-IV (Hasin et al, 2007) has raised serious questions regarding the extent of alcohol use disorder, and the relationship between alcohol abuse and alcohol dependence. While the adverse social, physical and mental effects of alcohol misuse are well known (Council on Scientific Affairs, 1996), there is little information on the determinants of alcohol abuse (societal impact) and alcohol dependence (physiological impact). We therefore examined their separate and combined associations with demographic, social and health characteristics in a representative communityresident sample aged 60 years and over. We hypothesised that, while for each of the three groups (those with alcohol abuse, those with alcohol dependence, and those with both) there would be associated demographic characteristics, abuse would be more closely associated with social characteristics, dependence with health characteristics, and the combined presence of abuse and dependence with both social and health characteristics. 


\section{Methods}

Data were gathered by carefully trained and monitored interviewers in 1995 using face-to-face structured household surveys of 7920 representative community residents aged 60 years and over, in nine regions covering the southernmost Brazilian state of Rio Grande do Sul (a wine-producing area). Information from one region was problematic and was dropped, resulting in a sample of 7040 persons, of whom 79 (1.1\%) declined to participate, yielding an analysis sample of 6961 (Conselho Estadual do Idoso, 1997). The ethics committee of the Federal University of São Paulo approved the study.

\section{Dependent variable: evaluation of alcohol use}

Use of alcohol was evaluated according to participants' yes/no responses to each of the following questions (asked in Portuguese):

1 Has a family member, friend, physician, priest ever commented or suggested that you were drinking too much?

2 Have you ever tried to stop drinking but been unable to do so?

3 Have you ever had trouble at work or school because of alcohol, such as drinking or missing work?

4 Have you ever been involved in fights or arrested for being drunk?

5 Has it ever seemed to you that you were drinking too much?

While not constituting an established measure, the individual items are comparable to those commonly used in similar surveys. A positive response to question 1, 3 or 4 was accepted as indicating lifetime abuse of alcohol. A positive response to question 2 or 5 indicated lifetime dependence (Hasin et al, 2007). Participants were not asked when the problem occurred. The sample was classified into four mutually exclusive groups: abuse only, dependence only, both abuse and dependence, neither abuse nor dependence.

\section{Independent variables}

The independent variables are listed in Table 1.

Physical activity (i.e. exercise) was assessed by asking: 'In the last 3 months have you practised regular physical activity?' Responses were recorded as 'yes' (once a week or more) or 'no'. Employment status was recorded as 'employed' if the participant was still working (the type of work was immaterial) or 'not employed' if not working or did not know the answer. Problems with activities of daily living $(A D L)$ were assessed using a five-item unidimensional scale. The number of impaired activities was recoded as 0,1 or 2 , or 3 or more.

Preliminary analyses of 18 self-reported physical health conditions indicated that only vascular conditions, respiratory problems, kidney problems and osteoporosis were relevant. Vascular conditions include any mention of heart disease, hypertension, diabetes, stroke or varicosities. Respiratory problems include any mention of bronchitis or pneumonia.

The presence of a psychiatric condition was assessed by a validated Brazilian modification of the Short Psychiatric Evaluation Schedule (Blay et al, 1988).

\section{Statistical analysis}

Percentages were used to describe the sample, and $\chi^{2}$ to compare each of the three alcohol use groups with the group recording neither lifetime abuse nor lifetime dependence. Because of the small size of the abuse-only group, separate blockwise logistic regression analyses were first run to identify the significant variables within each block (demographic, social, health characteristics - see Table 1). These significant variables were then entered into an initial multivariable polytomous logistic regression, and a final model was run using only the variables found to be significant. Analyses were performed using SPSS 13.0.

\section{Results}

Lifetime alcohol abuse was recorded for 734 participants $(10.6 \%)$, of whom $103(1.5 \%)$ reported abuse only, 244 (3.5\%) dependence only, and 387 (5.6\%) both abuse and dependence. Two-thirds of the sample were female, the majority were aged 60-69, of low education and low income, rural birth, White (84\%) and Catholic (75\%) (Table 1). In univariate analyses (Table 1) the 'abuse only' group differed from those with neither abuse nor dependence on 5 of the 21 characteristics examined (male, use tobacco, married, less likely to participate in religion-affiliated activities, and less likely to have osteoporosis). In addition to all these characteristics except religion-affiliated activities, 'dependence only' participants were more likely to be younger, of 'other' race/ ethnicity, employed and to have a respiratory condition, but less likely to report a vascular condition. Participants reporting abuse and dependence additionally had little education, were less likely to participate in social activities, and were more likely to have ADL problems, kidney problems and psychiatric problems.

The final controlled analysis (Table 2) yielded a more restricted set of significant variables, but showed a similar increase in number and type of associations, going from 'abuse only' to 'dependence only' to 'abuse and dependence'. The significant associates of 'abuse only' were male gender and tobacco use. 'Dependence only' was additionally associated with 'other' race/ethnicity (as compared with White), increased likelihood of respiratory and psychiatric problems, and decreased odds of vascular conditions. The same associations held for 'abuse and dependence', but with more marked odds ratios.

\section{Discussion}

The data come from a large community-resident sample aged 60 years and over, representative of the state of Rio Grande do Sul in Brazil, who provided information on multiple aspects of ageing. The five-item questionnaire permitted a rough assessment of lifetime alcohol abuse (three items) and alcohol dependence (two items). According to the responses to these items, $10.6 \%$ of the sample (men, 25.4\%; women, $2.9 \%$ reported alcohol-related problems, with $1.5 \%$ reporting abuse only, 3.5\% dependence only, and 5.6\% abuse and dependence.

Comparison with other studies in Brazil is difficult. Focus on lifetime use is infrequent; the samples rarely include participants aged 60 and over, are often small, resulting in questionable findings, and have used different measures to assess alcohol use. Our finding of a $10.6 \%$ prevalence rate 
Table 1 Basic descriptive characteristics of the sample by report of alcohol abuse only, dependence only, and abuse and dependence: numbers (\%) of participants

\begin{tabular}{|c|c|c|c|c|c|c|c|c|}
\hline \multirow{2}{*}{ Demographic characteristics } & \multicolumn{2}{|c|}{$\begin{array}{l}\text { Total sample } \\
(n=6961)\end{array}$} & \multicolumn{2}{|c|}{$\begin{array}{l}\text { Abuse only } \\
(n=103)\end{array}$} & \multicolumn{2}{|c|}{$\begin{array}{l}\text { Dependence only } \\
(n=244)\end{array}$} & \multicolumn{2}{|c|}{$\begin{array}{l}\text { Abuse and dependence } \\
(n=387)\end{array}$} \\
\hline & & & & & & & & \\
\hline \multicolumn{9}{|l|}{ Gender } \\
\hline Male & 2368 & $(34.0)$ & 74 & $(71.8)^{* * *}$ & 193 & $(79.1)^{* * *}$ & 332 & $(85.8)^{* * *}$ \\
\hline Female & 4593 & $(66.0)$ & 29 & $(28.2)$ & 51 & $(20.9)$ & 55 & $(14.2)$ \\
\hline \multicolumn{9}{|l|}{ Age (years) } \\
\hline $60-64$ & 1866 & $(26.8)$ & 32 & (31.1) & 84 & $(34.4)^{* * *}$ & 147 & $(38.0) * * *$ \\
\hline $65-69$ & 2085 & $(30.0)$ & 23 & $(22.3)$ & 82 & $(33.6)$ & 111 & $(28.7)$ \\
\hline $70-74$ & 1067 & $(15.3)$ & 19 & $(18.4)$ & 38 & $(15.6)$ & 55 & $(14.2)$ \\
\hline $75-79$ & 1216 & $(17.5)$ & 23 & $(22.3)$ & 24 & $(9.8)$ & 51 & $(13.2)$ \\
\hline $80+$ & 727 & $(10.4)$ & 6 & $(5.8)$ & 16 & $(6.6)$ & 23 & (5.9) \\
\hline \multicolumn{9}{|l|}{ Education } \\
\hline$<4$ years & 4594 & $(66.0)$ & 73 & (70.9) & 162 & $(66.4)$ & 293 & $(75.7)^{* * *}$ \\
\hline$>4$ years & 2344 & (34.0) & 30 & (29.1) & 81 & $(33.2)$ & 93 & $(24.0)$ \\
\hline Income & & & & & & & & \\
\hline Low income $(<$ US\$200) & 4323 & $(62.1)$ & 61 & $(59.2)$ & 147 & $(60.2)$ & 238 & (61.5) \\
\hline Higher income (>US\$200) & 2414 & $(34.7)$ & 40 & $(40.8)$ & 93 & $(38.1)$ & 134 & $(34.6)$ \\
\hline Race & & & & & & & & \\
\hline White & 5862 & $(84.2)$ & 84 & $(81.6)$ & 194 & $(79.5)^{* *}$ & 275 & $(71.1)^{* * *}$ \\
\hline Afro-Brazilian & 473 & (6.8) & 8 & (7.8) & 14 & (5.7) & 58 & $(15.0)$ \\
\hline Other & 625 & $(9.0)$ & 11 & $(10.7)$ & 36 & $(14.8)$ & 54 & $(14.0)$ \\
\hline Religion & & & & & & & & \\
\hline Catholic & 5245 & (75.3) & 83 & $(80.6)$ & 184 & (75.4) & 290 & (74.9) \\
\hline Evangelical & 1077 & $(15.5)$ & 10 & $(9.7)$ & 38 & $(15.6)$ & 51 & $(13.2)$ \\
\hline Other & 609 & $(8.7)$ & 10 & $(9.7)$ & 21 & (8.6) & 45 & $(11.6)$ \\
\hline Place of birth & & & & & & & & \\
\hline Urban & 2363 & (33.9) & 31 & $(30.1)$ & 76 & (31.1) & 121 & (31.3) \\
\hline Rural & 4529 & (65.1) & 69 & (67.0) & 167 & $(68.4)$ & 264 & $(68.2)$ \\
\hline Social characteristics & & & & & & & & \\
\hline Physical activity & & & & & & & & \\
\hline No & 4316 & $(62.0)$ & 61 & $(59.2)$ & 149 & $(61.1)$ & 247 & $(63.8)$ \\
\hline Yes & 2608 & $(37.5)$ & 42 & $(40.8)$ & 95 & (38.9) & 140 & $(36.2)$ \\
\hline Use tobacco & & & & & & & & \\
\hline Yes & 1302 & (18.7) & 37 & $(35.9)^{* * *}$ & 102 & $(41.8)^{* * *}$ & 182 & $(47.0)^{* * *}$ \\
\hline No & 5632 & (80.9) & 66 & $(64.1)$ & 142 & $(58.2)$ & 205 & $(53.0)$ \\
\hline Marital status & & & & & & & & \\
\hline Married & 3161 & $(45.4)$ & 63 & $(61.2)^{* * *}$ & 138 & $(56.6)^{* * *}$ & 219 & $(56.6)^{* * *}$ \\
\hline Never married & 471 & (6.8) & 10 & $(9.7)$ & 20 & $(8.2)$ & 38 & $(9.8)$ \\
\hline No longer married & 3328 & $(47.8)$ & 30 & $(29.1)$ & 86 & $(35.2)$ & 130 & $(33.6)$ \\
\hline Children & & & & & & & & \\
\hline Yes & 6492 & (93.3) & 101 & $(98.1)$ & 224 & $(91.8)$ & 364 & $(94.1)$ \\
\hline No & 445 & (6.4) & 2 & (1.9) & 20 & (8.2) & 21 & (5.4) \\
\hline Living arrangements & & & & & & & & \\
\hline Live with someone & 5893 & $(84.7)$ & 93 & $(90.3)$ & 207 & (81.9) & 328 & (84.8) \\
\hline Live alone & 1056 & $(15.2)$ & 10 & $(9.7)$ & 37 & $(18.1)$ & 59 & $(15.2)$ \\
\hline Employed & & & & & & & & \\
\hline No & 5992 & (86.1) & 92 & (89.3) & 196 & $(80.3) * *$ & 290 & $(74.9)^{* * *}$ \\
\hline Yes & 940 & (13.5) & 11 & $(10.7)$ & 46 & $(19.7)$ & 96 & $(24.8)$ \\
\hline Participate in social activities & & & & & & & & \\
\hline No & 4221 & $(60.6)$ & 70 & $(68.0)$ & 156 & (63.9) & 260 & $(67.2)^{* * *}$ \\
\hline Yes & 2736 & (39.3) & 33 & $(32.0)$ & 88 & (36.1) & 127 & $(32.8)$ \\
\hline Participate in religion-affiliatec & & & & & & & & \\
\hline No & 1977 & $(28.4)$ & 40 & $(38.8)^{*}$ & 80 & (32.8) & 161 & $(41.6)^{* * *}$ \\
\hline Yes & 4964 & (71.3) & 63 & $(61.2)$ & 164 & $(67.2)$ & 225 & $(58.1)$ \\
\hline Health characteristics & & & & & & & & \\
\hline Activities of daily living probl & & & & & & & & \\
\hline 0 & 4238 & $(60.9)$ & 62 & $(60.2)$ & 151 & (61.9) & 234 & $(60.5)^{* *}$ \\
\hline 1 or 2 & 2195 & (31.5) & 30 & $(29.1)$ & 79 & (32.4) & 108 & $(27.9)$ \\
\hline 3 or more & 526 & (7.6) & 11 & $(10.7)$ & 14 & $(5.7)$ & 45 & $(11.6)$ \\
\hline Vascular conditions & & & & & & & & \\
\hline Yes & 4390 & $(63.1)$ & 60 & $(58.3)$ & 124 & $(50.8)^{* * *}$ & 190 & $(49.1)^{* * *}$ \\
\hline No & 2542 & $(36.5)$ & 43 & $(41.7)$ & 120 & $(49.2)$ & 197 & $(50.9)$ \\
\hline Respiratory conditions & & & & & & & & \\
\hline Yes & 2059 & $(29.6)$ & 31 & $(30.1)$ & 95 & $(38.9)^{* * *}$ & 166 & $(42.9)^{* * *}$ \\
\hline No & 4902 & $(70.4)$ & 72 & (69.9) & 149 & $(61.1)$ & 221 & $(57.1)$ \\
\hline Kidney problems & & & & & & & & \\
\hline Yes & 897 & (12.9) & 16 & (15.5) & 27 & $(11.1)$ & 77 & $(19.9)^{* * *}$ \\
\hline No & 6066 & $(87.1)$ & 87 & (84.5) & 217 & (88.9) & 310 & $(80.1)$ \\
\hline Osteoporosis & & & & & & & & \\
\hline Yes & 1047 & $(15.0)$ & 6 & $(5.8)^{* *}$ & 25 & $(10.2)^{*}$ & 42 & $(10.9)^{* *}$ \\
\hline No & 5916 & $(85.0)$ & 97 & $(94.2)$ & 219 & $(89.8)$ & 345 & $(89.1)$ \\
\hline Psychiatric problem & & & & & & & & \\
\hline Yes & 2722 & (39.1) & 42 & $(40.8)$ & 110 & $(45.1)$ & 192 & $(49.6)^{* * *}$ \\
\hline No & 4241 & (60.9) & 61 & (59.2) & 134 & (54.9) & 195 & $(50.4)$ \\
\hline
\end{tabular}

Values may not total to $n$ and percentages may not sum to 100 because of missing data.

Chi square test: ${ }^{*} P<0.05 ;{ }^{* *} P<0.01 ;{ }^{* * *} P<0.001$ ('abuse only', 'dependence only', 'abuse and dependence' each compared with 'no abuse or dependence'). 
Table 2 Polytomous logistic regression comparing alcohol abuse only, alcohol dependence only, and both abuse and dependence with no reported alcohol abuse

\begin{tabular}{|c|c|c|c|c|c|c|}
\hline & \multicolumn{2}{|l|}{ Abuse only } & \multicolumn{2}{|l|}{ Dependence only } & \multicolumn{2}{|c|}{ Abuse and dependence } \\
\hline & OR $(95 \% \mathrm{Cl})$ & $P$ & OR $(95 \% \mathrm{Cl})$ & $P$ & OR $(95 \% \mathrm{Cl})$ & $P$ \\
\hline \multicolumn{7}{|l|}{ Demographic characteristics } \\
\hline \multicolumn{7}{|l|}{ Gender } \\
\hline Male & $6.32(4.04,9.18)$ & 0.001 & $9.08(6.57,12.54)$ & 0.001 & $15.44(11.40,20.89)$ & 0.001 \\
\hline \multicolumn{7}{|l|}{ Race } \\
\hline White & $0.86(0.45,1.64)$ & 0.644 & $0.64(0.44,0.95)$ & 0.025 & $0.63(0.45,0.89)$ & 0.007 \\
\hline Afro-Brazilian & $1.25(0.49,3.17)$ & 0.639 & $0.73(0.38,1.40)$ & 0.340 & $2.16(1.38,3.36)$ & 0.001 \\
\hline Other & Reference & & Reference & & Reference & \\
\hline \multicolumn{7}{|l|}{ Social characteristics } \\
\hline Use tobacco & $2.21(1.45,3.37)$ & 0.001 & $2.44(1.85,3.22)$ & 0.001 & $2.77(2.20,3.49)$ & 0.001 \\
\hline \multicolumn{7}{|l|}{ Health characteristics } \\
\hline Vascular condition present & $0.99(0.65,1.50)$ & 0.944 & $0.71(0.54,0.94)$ & 0.017 & $0.65(0.51,0.82)$ & 0.001 \\
\hline Respiratory condition present & $0.94(0.61,1.47)$ & 0.797 & $1.35(1.02,1.78)$ & 0.038 & $1.51(1.20,1.91)$ & 0.001 \\
\hline Psychiatric problem present & $1.50(0.98,2.30)$ & 0.063 & $1.91(1.43,2.54)$ & 0.001 & $2.36(1.85,3.00)$ & 0.001 \\
\hline
\end{tabular}

The variables considered are the demographic, social and health conditions listed in Table 1. The significant variables identified in a blockwise analysis were entered into a penultimate polytomous multivariable logistic regression model, from which the resulting significant variables were then selected for the current, final model.

compares with reports ranging from $2.7 \%$ in Campinas, south-eastern Brazil (based on 93 participants aged 60 and over) (Barros et al, 2007) to $12 \%$ for frequent or heavy drinkers in a sub-sample aged 60 years and over in a national survey (Laranjeira et al, 2007).

The demographic and health associations of alcohol misuse we found are comparable to those reported elsewhere, which implicate male gender, younger age, tobacco use, adverse physical health conditions except for vascular status, and adverse psychiatric status (National Institute on Alcohol Abuse and Alcoholism, 2002), providing confidence that the five alcohol questions have both content and criterion validity.

We hypothesised that 'abuse only' would be associated with demographic and social variables, and 'dependence only' with health-related characteristics. In controlled analyses, our hypothesis regarding 'abuse only' held, but characteristics associated with dependence included both health conditions (as hypothesised) and characteristics encompassed by 'abuse only'. The same 'dependence only' characteristics held for 'abuse and dependence', but the associations were stronger.

Our findings also address two key questions: whether 'abuse only', 'dependence only' and 'abuse and dependence' are hierarchically associated; and whether they represent unique, non-progressive, manifestations of alcohol misuse. We argue for hierarchical association based on the finding that, in these older persons, dependence is uniquely associated with health effects in addition to the effects associated with alcohol abuse, and that these associations are intensified among those reporting abuse and dependence. We argue for the possibility of non-progression by noting that nearly half of those reporting lifetime alcohol misuse report only lifetime abuse, or only lifetime dependence. Since lifetime alcohol abuse has consistently been reported to decline with age (a finding further confirmed even in this older sample), we assume (but cannot confirm) that alcohol abuse occurred at an earlier time and may not necessarily progress. In support, Hasin et al (1990) found that, over 4 years, only 30\% progressed from alcohol abuse only to alcohol dependence, while 39\% with alcohol dependence had remitted.

Our data have significant limitations. Our measure does not meet diagnostic criteria, so our findings must be interpreted cautiously. Information is self-reported; however, self-report has been found to be valid for alcohol use and problems (Bongers \& Van Oers, 1998) and for various health conditions (Beckett et al, 2000). We have no information on when problems with alcohol use occurred and whether they were still present. This cross-sectional design cannot distinguish between cause and effect.

Nevertheless, these data suggest that, while there is a gradient of associations and of adverse effects going from 'abuse' to 'dependence' to 'abuse and dependence', progression to a more serious stage need not necessarily occur.

\section{Acknowledgements}

We thank Dr Sergio Antônio Carlos, President of the State Council of the Elderly (Conselho Estadual do Idoso), for allowing us to use the dataset of the study 'Elderly of RS - a multidimensional study of their living conditions'.

This study was supported by grants from Conselho Estadual do Idoso, Secretaria do Trabalho, Cidadania e Assistência Social; and by Governo do Estado do Rio Grande do Sul. Dr Fillenbaum was partially supported by National Institute on Aging grant number 1P30 AG028716-01 Claude D. Pepper OAIC.

\section{References}

Barros, M. B. A., Botega, N. J., Dalgalarrondo, P., et al (2007) Prevalence of alcohol abuse and associated factors in a population-based study. Revista de Saúde Pública, 41, 502-509.

Beckett, M., Weinstein, M., Goldman, N., et al (2000) Do health interview surveys yield reliable data on chronic illness among older respondents? American Journal of Epidemiology, 151, 315-323.

Blay, S. L., Ramos, L. R. \& Mari, J. J. (1988) Validity of a Brazilian version of the Older Americans Resources and Services (OARS) mental health screening questionnaire. Journal of the American Geriatrics Society, 36, 687-692.

Bongers, I. M. \& Van Oers, J. A. (1998) Mode effects on self-reported alcohol use and problem drinking: mail questionnaires and personal interviewing compared. Journal of Studies on Alcohol, 59, 280-285.

Conselho Estadual do Idoso (1997) Os idosos do Rio Grande do Sul: Estudo Multidimensional de suas Condições de Vida. Relatório de Pesquisa. [The elderly of Rio Grande do Sul: multidimensional assessment of their living conditions. Report of findings.] Conselho Estadual do Idoso.

Council on Scientific Affairs, American Medical Association (1996) Alcoholism in the elderly. JAMA, 275, 797-801

Hasin, D. S., Grant, B. F. \& Endicott, J. (1990) The natural history of alcohol abuse: implications for definitions of alcohol use disorders. American Journal of Psychiatry, 147, 1537-1541. 
Hasin, D. S., Stinson, F. S., Ogburn, E., et al (2007) Prevalence, correlates, disability, and comorbidity of DSM-IV alcohol abuse and dependence in the United States: results from the National Epidemiologic Survey on Alcohol and Related Conditions. Archives of General Psychiatry, 64, 830-842

Laranjeira, R., Pinsky, I., Zaleski, M., et al (2007) / Levantamento nacional sobre os padrões deconsumo de álcool na população brasileira. [National survey on patterns of alcohol use in the population of
Brazil.] Presidência da República Gabinete de Segurança Institucional Secretaria Nacional Antidrogas Brasília, DF.

National Institute on Alcohol Abuse and Alcoholism (2002) Alcohol Consumption and Problems in the General Population: Findings from the 1992 National Longitudinal Alcohol Epidemiologic Survey, NIH Publication No. 02-4997. National Institutes of Health, National Institute on Alcohol Abuse and Alcoholism.

\title{
The relationship between socio-economic status and mental health funding, service provision and national policy: a cross-national study
}

\author{
Ajit Shah
}

Professor of Ageing, Ethnicity and Mental Health, University of Central Lancashire, Preston, UK email ajit.shah@wlmht.nhs.uk

\begin{abstract}
recent editorial in International Psychiatry (Cox, 2008)
described the importance of a new initiative by the Lancet (Horton, 2007) to promote the development and delivery of mental health services and treatments in lowand middle-income countries (LMICs). This initiative was supported by a series of outstanding papers (Chisholm et al, 2007; Jacob et al, 2007; Patel et al, 2007; Saraceno et al, 2007; Saxena et al, 2007).

The availability of generic mental health services in individual countries is contingent upon several factors. First, there is a need for a national mental health policy (Jacob et al, 2007; Saxena et al, 2007). Although $80 \%$ of countries had a national mental health policy, LMICs were less likely to have one (Jacob et al, 2007). Second, there is a need for a national plan for the implementation of that policy (Saxena et al, 2007). Third, mental health services actually need to be developed and delivered (Saxena et al, 2007). LMICs, compared with high-income countries (HICs), have poor resources, including fewer psychiatric beds and fewer doctors, nurses, psychiatrists and other mental health professionals (Jacob et al, 2007), per head of population. Fourth, the availability of effective and cost-effective treatment interventions is important in the design, development and delivery of mental health services (Chisholm et al, 2007; Patel et al, 2007). All these sequential steps are underpinned by satisfactory funding (Jacob et al, 2007; Saxena et al, 2007). LMICs, compared with HICs, spend a lower proportion of their gross domestic product (GDP) on health, are less likely to have a dedicated mental health budget and, when such a dedicated budget exists, it forms a lower proportion of the total health budget (Jacob et al, 2007; Shah, 2007).

The five seminal Lancet papers primarily used the World Bank categorisation of LMICs and HICs as a categorical variable in their data analyses. Similar analyses are repeated in this study instead using GDP (a continuous variable) as
\end{abstract}

a measure of socio-economic status. Additionally, similar analyses were repeated using a measure of income inequality, the Gini coefficient.

\section{Methods}

Data on GDP for the year 2002 were taken from the website of the World Health Organization (WHO) (http://www. who.int/countries/en). The website of the United Nations Development Programme (http://hdr.undp.org/en/reports/ nhdr) provided data on the Gini coefficient; a higher Gini coefficient suggests greater income inequality. The median (range) year when the latest data on the Gini coefficient were available was 2000 (range 1983-2003).

Box 1 lists the precise parameters examined for national policy on mental health, funding for mental health services and mental health service provision. Data on mental health funding, service provision and national policy were ascertained from the Mental Health Atlas 2005 (http://www.who. int/GlobalAtlas) published by the WHO.

The relationship between GDP and the Gini coefficient and the continuous variables (see Box 1) was examined using Spearman's rank correlation coefficient (rho). The relationship between GDP and the Gini coefficient and the dichotomous variables (see Box 1) was examined using the Mann-Whitney $U$-test (reported below with the $Z$ statistic).

\section{Results}

A total of 192 countries were listed on the WHO website. Data on the different measured parameters were available for a median (range) of 187 (100-191) countries. With the exceptions of the Gini coefficient $(n=125)$ and percentage of the health budget spent on mental health $(n=100)$, 